\title{
Des surfactants « verts " préparés à partir de fractions protéiques industrielles de colza
}

Oléagineux, Corps Gras, Lipides. Volume 10, Numéro 5-6, 360-4, Double 5-6, SEPTEMBRE-OCTOBRENOVEMBRE-DÉCEMBRE 2003, UTILISATIONS ET APPLICATIONS DES MATIÈRES PREMIÈRES RENOUVELABLES

Auteur(s) : Colette LARRÉ, Serge BÉROT, Raul SANCHEZ-VIOQUE, Jacques GUÉGUEN, Unité de recherche sur les protéines végétales et leurs interactions, Institut national de la recherche agronomique (INRA), rue de la Géraudière, BP 71627, 44316 Nantes cedex 03, France .

Author(s) : Colette LARRÉ, Serge BÉROT, Raul SANCHEZ-VIOQUE, Jacques GUÉGUEN

Summary : Edible surfactants were prepared from rapeseed meal by functionalization of two types of products: proteins or peptide fractions obtained by enzymatical hydrolysis. Functionalization aimed to enhance the amphophilic characteristics of the products by grafting hydrophobic chains〉; it was based on acylation or sulfamidation of proteins and acylation of peptides. The interfacial properties of these "green" surfactants measured by lowering the surface tension, and increasing the stability of foams and emulsions, were improved, depending on the chemical reagent used. For example, peptides modified by $\mathrm{C}_{4}{ }_{4}$ acyl chlorides exhibited the better emulsifying properties, whereas the better foaming properties were obtained with peptides modified by $C_{10}$ and $C_{12}$ acyl chlorides. These surfactants could diversify the uses of rapeseed derivatives, particularly in non food industries.

Keywords : surfactants, rapeseed, proteins, peptides, functionality, surface activity

\section{ARTICLE}

Auteur(s) : Colette LARRÉ, Serge BÉROT, Raul SANCHEZ-VIOQUE, Jacques GUÉGUEN

Unité de recherche sur les protéines végétales et leurs interactions, Institut national de la recherche agronomique (INRA), rue de la Géraudière, BP 71627, 44316 Nantes cedex 03, France

Les protéines de colza sont actuellement sous exploitées car uniquement valorisées en alimentation animale. Cependant l'intérêt pour des applications non alimentaires de ces co-produits de l'industrie agroalimentaire s'intensifie du fait de leur caractère renouvelable et biodégradable associé à leur faible coût et ouvre de nouveaux secteurs d'application. Un projet européen (Enhance) incluant des partenaires publics et industriels a été conduit afin d'explorer de nouvelles voies d'utilisation pour les fractions protéiques du colza. De nouveaux marchés ont été envisagés dans le secteur des matériaux d'isolation, des colles, du papier, des cosmétiques ou des détergents... Dans le cadre de ce programme européen mais aussi d'un contrat national Ademe, des résultats intéressants exploitant les propriétés tensioactives de ces protéines et des peptides dérivés ont été obtenus. La préparation de ces molécules tensioactives a requis la mise en place d'étapes de modifications chimiques et enzymatique des protéines de colza qui sont décrites dans cet article. 
Les agents tensioactifs capables d'abaisser fortement la tension superficielle d'un liquide sont en général de petites molécules amphiphiles constituées d'un pôle hydrophile et d'un pôle hydrophobe bien distincts. Ces molécules diffusent rapidement vers l'interface et au cours du processus de moussage ou d'émulsification stabilisent les bulles de gaz ou les gouttelettes d'huile dès leur formation. Elles favorisent ainsi la stabilisation de la phase dispersée. Les protéines sont bien connues pour leurs propriétés tensioactives car elles présentent aussi des régions hydrophiles et des régions hydrophobes pouvant s'organiser spatialement en boucle dans les phases polaire et apolaire respectivement, tandis que les régions indifférentes peuvent constituer des trains, séquences situées dans le plan de l'interface. On ne peut donc pas parler réellement dans le cas des protéines de pôles hydrophiles et hydrophobes comme dans le cas des agents tensioactifs de synthèse. Du fait de ces caractéristiques structurales plus complexes, les protéines sont en général moins efficaces que les tensioactifs pour abaisser la tension interfaciale. Ce phénomène se trouve accentué par la diffusion plus lente des protéines vers l'interface en raison de leur masse plus élevée. Il en résulte, pour les émulsions stabilisées par des protéines, une plus grande taille des gouttelettes d'huile. Par contre, in fine, bien que l'adsorption à l'interface des protéines soit complexe et beaucoup plus lente, leur utilisation permet une bonne stabilisation du film interfacial, grâce à leurs propriétés électrostatiques et rhéologiques qui limitent respectivement la floculation et la coalescence des gouttelettes.

Sur la base de ces acquis, les travaux que nous avons conduits au cours de ces dernières années ont eu pour objectifs de développer des molécules tensioactives à partir des protéines de colza ( $2 \mathrm{~S}$ ou napine, $12 \mathrm{~S}$ ou cruciférine) en développant deux stratégies complémentaires :

- modifier la balance hydrophile/hydrophobe des protéines par greffage de molécules hydrophobes ;

- générer à partir de ces protéines des peptides et accroître leur amphiphilicité par greffage de chaînes hydrophobes.

D'un point de vue finalisé, le développement de tensioactifs peptidiques présente un avantage certain, pour l'utilisation des protéines des tourteaux industriels. Difficiles à extraire après les traitements très dénaturants de trituration, ces protéines peuvent par contre être facilement solubilisées sous forme d'extraits peptidiques par traitement protéolytique du tourteau.

\section{Fonctionnalisation de protéines ou peptides par acylation et sulfonylation}

Le greffage de chaînes hydrophobes sur les protéines et les peptides est effectué par acylation des groupements amines. L'acétylation et la succinylation ont été très largement employées afin de modifier l'état de charge des protéines [1, 2]. En utilisant d'autres réactifs d'acylation, il est possible d'incorporer des chaînes aliphatiques non chargées ou des chaînes aromatiques et donc d'introduire un groupement hydrophobe sur une protéine [3]. Parmi ces réactifs, on trouve des anhydrides $\left(\mathrm{R}_{1}-\mathrm{CO}_{2}\right) \mathrm{O}$, des chlorures d'acyles $\left(\mathrm{R}_{2}-\mathrm{COCl}\right)$ et des chlorures de sulfonyl $\left(\mathrm{R}_{3}-\mathrm{SO}_{2} \mathrm{Cl}\right)$ qui vont permettre le remplacement d'un atome d'hydrogène de la fonction amine $\left(\mathrm{NH}_{2}\right)$ par un radical acyle $\mathrm{R}_{1}-\mathrm{CO}-, \mathrm{R}_{2}-\mathrm{CO}-, \mathrm{R}_{3}-\mathrm{SO}_{2}$ - ou $\mathrm{R}_{4}-\mathrm{C}_{6} \mathrm{H}_{5}-\mathrm{SO}_{2}$.

L'hydrophobation des protéines a été effectuée en utilisant des chaînes aliphatiques de longueur variable $\left(\mathrm{CH}_{3}-\left(\mathrm{CH}_{2}\right) \mathrm{n}\right)$ avec $\mathrm{n}$ variant de 2 à 6 . Appliquées aux protéines de réserve du colza purifiées $(2 \mathrm{~S}, 12 \mathrm{~S})$ (tableau 1), ces réactions donnent des rendements variables modulés en fonction de la 
protéine considérée et globalement décroissants avec la longueur de la chaîne aliphatique $R_{1}$. Les plus faibles rendements de modification obtenus avec la $12 \mathrm{~S}$ s'expliquent par la structure de cette protéine et la moindre accessibilité de ses groupements amines; cependant ces rendements peuvent être augmentés en utilisant un très large excès de réactifs. Dans tous les cas, la fonctionnalisation par les chlorures de sulfonyl se révèle moins efficace probablement à cause de l'encombrement stérique créé par le groupement arylsulfonyl utilisé $\left(\mathrm{R}_{4}-\mathrm{C}_{6} \mathrm{H}_{5}-\mathrm{SO}_{2} \mathrm{Cl}\right)$. C'est probablement pour cette raison que l'introduction de radicaux par l'intermédiaire de chlorures de sulfonyl induit des modifications conformationnelles des protéines plus importantes qu'avec les chlorures d'acyle.

Tableau 1. Pourcentage de modification des protéines purifiées de colza, napine (2S) et cruciférine (12S), en utilisant 3 équivalents d'anhydride et 2 équivalents de chlorure de sulfonyle par résidu lysine.

\begin{tabular}{|l|l|l|}
\hline Réactif & \% modification & \\
\hline & Napine (2S) & $62(0,52)$ \\
\hline Anhydride acétique $\left(C^{2}\right)$ & $95(0,45)$ & $49(0,52)$ \\
\hline Anhydride propionique $\left(C^{2}\right)$ & $65(0,60)$ & $64(0,63)$ \\
\hline Anhydride butyrique $\left(C^{4}\right)$ & $93(0,83)$ & $52(0,32)$ \\
\hline Anhydride hexanoique $\left(C^{6}\right)$ & $89(0,21)$ & $46(1,8)$ \\
\hline Chlorure de paratoluènesulfonyl $\left(C^{1}\right)$ & $43(0,83)$ & $43(0,95)$ \\
\hline Chlorure d'éthylbenzènesulfonyl $\left(C^{2}\right)$ & $37(0,50)$ & \\
\hline
\end{tabular}

D'un point de vue physico-chimique, l'hydrophobicité de surface des protéines est dans tous les cas augmentée et proportionnelle au nombre de chaînes aliphatiques introduites. Ces deux paramètres, flexibilité et hydrophobicité de surface, sont particulièrement influents sur le comportement interfacial d'une macromolécule [4]; leur accroissement tend à augmenter la cohésion et la résistance à la pression des films interfaciaux air-eau. Par exemple, dans le cas de la protéine $2 \mathrm{~S}$ de colza, le greffage d'une chaîne hexanoyle augmente la pression de collapse de 20 à $30 \mathrm{mN} / \mathrm{m}$. Ces propriétés laissent présager une aptitude à former des films interfaciaux stables dans des systèmes mousse ou émulsion.

Ces mêmes réactions de greffage ont été appliquées à des hydrolysats peptidiques issus de ces protéines. Il a donc été envisagé d'effectuer une hydrolyse à partir des protéines purifiées [1] mais aussi à partir de tourteaux ou d'isolats de colza puis de modifier ces peptides par acylation avec pour objectif de produire des surfactants « verts ».

Parmi les enzymes testées, l'alcalase a été retenue pour son efficacité d'une part, mais aussi pour sa disponibilité et son faible coût. Cette enzyme fonctionnant à des $\mathrm{pH}$ basiques et à des températures 
élevées $\left(50^{\circ} \mathrm{C}\right)$, il a été possible de mettre en suspension les tourteaux de colza et de conduire une hydrolyse poussée. La fraction soluble ainsi obtenue est composée de peptides correspondant pour $78 \%$ d'entre eux à un enchaînement de 5 à 6 acides aminés. Les résultats obtenus sur les protéines ont mis en évidence une modulation forte de la fonctionnalisation en liaison avec la longueur et la quantité des chaînes greffées. Des chlorures d'acyle de longueur de chaîne variant de C6 à C16 ont été testés afin de renforcer le pôle hydrophobe du peptide acylé. L'optimisation de la réaction d'acylation a permis l'obtention de bons rendements de modification (tableau 2) variants entre 71 et $94 \%$.

Tableau 2. Proportion de groupements amines modifiés sur un hydrolysat de tourteau de colza.

\begin{tabular}{|l|l|}
\hline Type de chaîne greffée & \% modificationdes groupements amines \\
\hline Hexanoyl $\left(C_{6}\right)$ & 71 \\
\hline Octanoyl $\left(C_{8}\right)$ & 85 \\
\hline Décanoyl $\left(C_{10}\right)$ & 94 \\
\hline Lauroyl $\left(C_{12}\right)$ & 84 \\
\hline Myristoyl $\left(C_{14}\right)$ & 77 \\
\hline Palmitoyl $\left(C_{16}\right)$ & 68 \\
\hline
\end{tabular}

\section{Systèmes biphasiques}

Les mousses comme les émulsions s'obtiennent à partir de deux phases non miscibles : air/eau ou eau/liquide non polaire. Leur formation nécessite un apport d'énergie qui provoque une augmentation de l'interface entre les deux phases. Ces systèmes thermodynamiquement instables peuvent être stabilisés par l'utilisation d'agents tensioactifs. Ces molécules sont souvent des composés organiques amphiphiles qui ont la particularité de s'arranger à l'interface en orientant leurs groupements hydrophiles vers la phase polaire et leurs groupements hydrophobes plutôt vers la phase apolaire.

Les protéines et peptides de par leur enchaînement en acides aminés constitutifs peuvent faire partie de cette catégorie de substances. Les modifications selon leur nature peuvent accroître la fréquence des pôles hydrophiles ou hydrophobes et donc engendrer des comportements interfaciaux modifiés. L'introduction de chaînes aliphatiques sur une protéine va conduire à une augmentation de sa proportion de pôles hydrophobes; dans le cas des peptides de petite taille et donc plutôt hydrophiles, on va obtenir une molécule très amphiphile. Il est donc préférable comme dans le cas décrit ici d'hydrolyser fortement les protéines puis de fonctionnaliser les petits peptides obtenus pour les rendre tensioactifs. 


\section{Propriétés moussantes}

Les propriétés moussantes peuvent être définies par deux facteurs: (1) la capacité à réduire la tension superficielle à l'interface, qui gouverne l'aptitude à former une mousse stable; (2) la stabilité de la mousse. Le premier facteur se teste par des mesures de tension de surface entre la solution et l'air et par le volume de mousse formé, le second par l'étude des cinétiques de drainage de la mousse et la variation du volume de mousse au cours du temps (figure 1).

\section{Protéines}

Concernant la fraction napine (2S), sa capacité moussante est peu modifiée par l'acylation et la sulfamidation, excepté dans le cas du dérivé éthylbenzène sulfonyl. Par contre le drainage est ralenti pour les protéines modifiées et le volume de mousse très stable. Le volume résiduel de mousse après 20 minutes est de $80 \%$ pour le dérivé éthylbenzène sulfonyl alors qu'il n'est que de $60 \%$ pour la protéine native. Dans le cas de la cruciférine (12S), l'influence de la lipophilisation est plus importante. On observe une réelle amélioration de la capacité moussante et une plus grande stabilité de la mousse.

\section{Peptides}

Les peptides constitués de 4 à 6 acides aminés sont, du fait de leur taille, plutôt hydrophiles et incapables d'abaisser la tension interfaciale air-eau (figure 2). L'introduction covalente de chaînes alkylées améliore globalement leur affinité pour l'interface avec un effet notable de la longueur de la chaîne introduite [2]. En effet, l'alkylation par des longueurs de chaînes de $C_{10}$ et $C_{12}$ a permis I'obtention de dérivés tensioactifs dont le comportement se rapproche plus de celui des détergents que de celui des protéines. Parmi ces dérivés peptidiques, seuls ceux obtenus avec des longueurs de chaîne de 10 et 12 carbones présentent un bon pouvoir moussant, comparable à celui de la sérum albumine bovine $(S A B)$ et légèrement inférieur à celui du sodium dodecyl sulfate (SDS). Leur capacité de rétention de liquide est intermédiaire entre celle d'une protéine et celle d'un détergent. Par contre les bulles formées sont particulièrement stables au cours du temps (figure 3). La faible coalescence des bulles au cours du vieillissement met en évidence la réelle capacité de ces dérivés à stabiliser durablement l'interface air-eau contrairement à ce que l'on observe pour le SDS. Les bonnes propriétés moussantes de ces dérivés protéiques ou peptidiques permettent d'envisager leur utilisation comme agents moussants "verts " d'autant plus qu'ils ont été obtenus par des techniques simples, peu coûteuses et extrapolables à une échelle industrielle.

\section{Propriétés émulsifiantes}

Les propriétés émulsifiantes peuvent être décrites par trois facteurs: la taille des gouttelettes d'huile et leur évolution dans le temps (tableau 3), la cinétique de floculation-crémage (figure 4) et enfin la résistance à la coalescence, c'est-à-dire l'aptitude de l'émulsion à résister à un traitement mécanique tel que la centrifugation (figure 5). 
Tableau 3. Taille moyenne des gouttelettes $(\mu \mathrm{m})$ exprimée en masse d'émulsion préparées avec du $S D S$, de la $S A B$, des peptides acylés C10-C14 et non acylés $(1 \mathrm{mg} / \mathrm{ml})$ dans $0,1 \mathrm{M}$ de tampon phosphate de sodium $\mathrm{pH} 7,0$.

\begin{tabular}{|l|l|l|}
\hline & Après 3min & Après 5 min \\
\hline SDS & 2,54 & 1,77 \\
\hline SAB & 13,85 & 13,90 \\
\hline C10 & 31,14 & $>80$ \\
\hline C12 & 30,11 & 40,65 \\
\hline C14 & 17,25 & 18,81 \\
\hline
\end{tabular}

\section{Protéines}

L'étude des propriétés émulsifiantes des protéines natives et modifiées montre que l'acylation et la sulfamidation n'ont pas les mêmes effets sur les cinétiques de floculation-crémage et sur les mécanismes de coalescence. En général, le greffage de chaînes hydrophobes accroît le phénomène de déstabilisation des émulsions par floculation-crémage. En revanche, il apparaît que ces protéines modifiées augmentent considérablement la résistance des émulsions vis-à-vis des phénomènes de coalescence. Cela suggère une modification importante des propriétés rhéologiques de la couche interfaciale due aux interactions hydrophobes entre protéines au sein de cette couche.

\section{Peptides}

Les peptides sans ou après fonctionnalisation par acylation à l'aide de chlorures d'acides gras ayant des longueurs de chaînes de 10 à 14 carbones ont été comparés comme précédemment avec le SDS et la sérum albumine bovine (SAB). Les émulsions stabilisées par le SDS sont fines, même après stockage, et sont peu sujettes à la floculation et au crémage mais résistent très mal à la coalescence. Ce comportement est assez caractéristique de celui des émulsions stabilisées par des tensioactifs de faible taille qui ne confèrent en général pas de résistance mécanique au film interfacial.

La taille des gouttelettes dans les émulsions stabilisées par la SAB est plus importante. Malgré cela ces émulsions sont stables; le phénomène de floculation-crémage est limité et les émulsions résistent remarquablement bien à la coalescence, montrant l'intérêt des macromolécules pour stabiliser le film interfacial. Les émulsions stabilisées par les peptides acylés de colza présentent des gouttelettes de tailles un peu plus élevées (tableau 3). Les peptides acylés par les chlorures en $\mathrm{C}_{14}$ donnent les meilleurs résultats : taille proche des émulsions stabilisées par la SAB et émulsions stables dans le temps. Les peptides acylés en $C_{12}$ sont également plus efficaces que ceux acylés en $C_{10}$. La comparaison des émulsions réalisées en présence de SDS et des peptides acylés en $C_{12}$ (même chaîne alkylée) montre que les groupes sulfate du SDS sont plus efficaces que les peptides pour générer des émulsions de petite taille. 
Les cinétiques de floculation-crémage des émulsions stabilisées par les peptides acylés sont intermédiaires entre celles des émulsions témoin stabilisées par le SDS et celles, très peu résistantes, des peptides non acylés (figure 4). Les émulsions stabilisées par les peptides acylés en C14 résistent un peu mieux que les autres à la floculation-crémage.

La résistance des émulsions à la coalescence permet encore un classement des peptides acylés (figure 5) : les résultats obtenus avec les peptides acylés en $C_{14}$ sont proches de ceux obtenus avec la $S A B$, tandis que les peptides acylés en $C_{12}$ donnent des résultats proches de ceux du SDS et que les peptides acylés en $\mathrm{C} 10$ donnent les films les moins résistants à la coalescence.

En résumé, plus la chaîne greffée sur les peptides de colza est longue, meilleures sont les propriétés émulsifiantes. En particulier, les résultats les plus remarquables sont obtenus avec les peptides greffés en $\mathrm{C}_{14}$ : taille de gouttelettes plus faible et stable, meilleure résistance à la floculationcrémage et surtout à la coalescence. Ainsi, ces peptides ont un comportement intermédiaire entre celui des surfactants de synthèse (faible taille des gouttelettes) et celui des protéines (résistance à la coalescence).

\section{Conclusion}

Ces études mettent en évidence à travers un exemple des voies nouvelles pour l'utilisation des protéines de tourteau d'oléagineux comme celles du tourteau de colza, dont le domaine d'utilisation est aujourd'hui limité au marché à faible valeur ajoutée de l'alimentation animale.

Les propriétés tensioactives remarquables des protéines et peptides modifiés associées à leur caractère biodégradable permettent d'envisager des utilisations dans des domaines où la dépollution des effluents et/ou la préservation de l'environnement sont essentiels comme les produits lessiviels industriels. La très grande stabilité des volumes de mousses associée au drainage de la phase aqueuse pourrait constituer des caractéristiques favorables à une utilisation dans les mousses mises en œuvre pour la lutte contre le feu.

Outre ces exemples, le programme Enhance que nous avons coordonné a démontré les potentialités de ces protéines et peptides comme adhésifs dans les colles et pour le traitement de surface des papiers.

La modification des protéines entières reste malgré tout la voie la plus difficile car cela suppose de préserver au cours des traitements de trituration le caractère de solublité de ces protéines pour pouvoir les extraire. L'application immédiate de ces travaux s'avère par contre plus facile dans le cas des peptides modifiés. Il suffit alors de traiter par voie enzymatique le tourteau de colza. Des essais pilote ont été effectués dans ce sens et se sont montrés concluants.

\section{Remerciements}

Ces travaux ont été partiellement financés par le contrat européen Enhance (QLK5 CT 1999 01442) et le contrat Ademe ( $\left.N^{\circ} 0101023\right)$. 


\section{RÉFÉRENCES}

1. Colette Larré, Klaus D. Schwenke, 1996, Modifications chimiques et enzymatiques des protéines végétales, Ed B. Godon, Protéines Végétales, Lavoisier Tec DOC, Paris, 468-517.

2. Schwenke KD, Mothes R, Raab B, Rawel H, Gueguen J. Selected physico-chemical properties of succinylated legumin from pea (Pisum sativum L.), Nahrung, 1993 ; 37(6) : 519-27.

3. A. Gerbanowski, C. Rabiller, C. Larré and J. Gueguen 1999, Grafting of aliphatic and aromatic probes on bovine serum albumin : influence on its structural and physicochemical characteristics, $J$ Protein Chem, 18 ; 3 : 325-35.

4. Alice Gerbanowski, Claude Rabiller and Jacques Guéguen, 2003 Behaviors of bovine serum albumin and rapeseed proteins at the air/water interface after grafting aliphatic or aromatic chains. J Colloid and Interface Science, Vol. $262 ; 2$ : 391-9.

5. Christophe Malabat, Raúl Sánchez-Vioque, Claude Rabiller, and Jacques Guéguen, Emulsifying and Foaming Properties of Native and Chemically Modified Peptides from the $2 \mathrm{~S}$ and $12 \mathrm{~S}$ proteins of rapeseed (Brassica napus L.) JAOCS, Volume 78 : 235-41.

6. Raúl Sánchez-Vioque, Christian L. Bagger, Colette Larré and Jacques Guéguen, 2003 Emulsifying properties of acylated rapeseed (Brassica napus L.) peptides. J Colloid and Interface Science. Sous presse. 


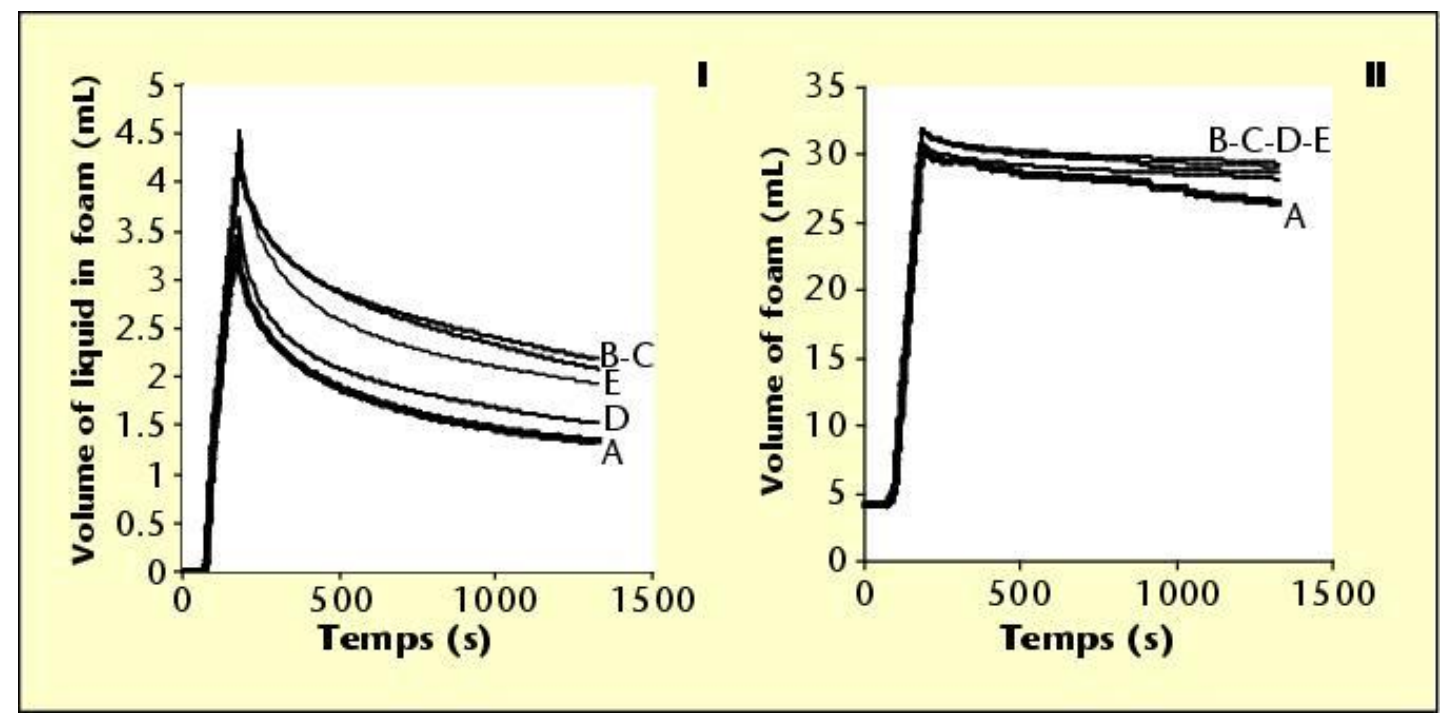

Figure 1. Propriétés moussantes des cruciférines (12S) natives et lipophilisées. Concentration protéique : $0,5 \mathrm{mg} / \mathrm{mL}$, tampon phosphate $0,1 \mathrm{M}, \mathrm{pH} 7,5 . \mathrm{I}$ : volume de liquide dans la mousse ; II : Volume de la mousse

A : native $12 S$; B : $125 /$ anhydride butanoïque (64\%) ; $:$ 12S/anhydride hexanoïque ; D : $125 / p$ toluènesulfonyle (46\%) ; $\mathrm{E}: 12 \mathrm{~S} /$ éthylbenzenesulfonyle (43\%).

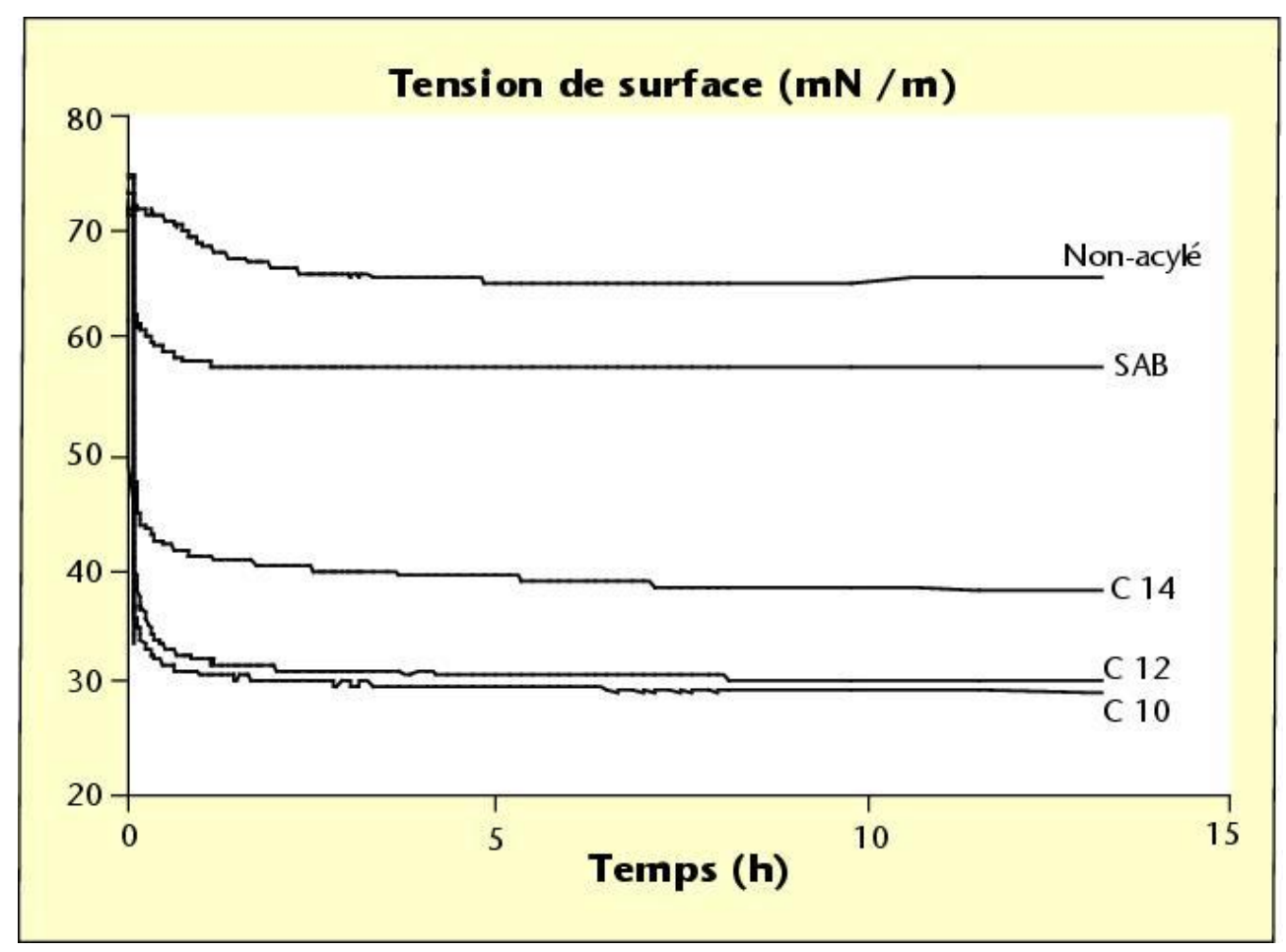

Figure 2. Cinétiques d'abaissement de la tension de surface mesurées en présence de tampon phosphate 0,1 M pH 7 pour différents produits : des peptides non acylés, de la SAB et des peptides acylés avec des chaînes de longueur différentes $C_{10}, C_{12}, C_{14}$. 


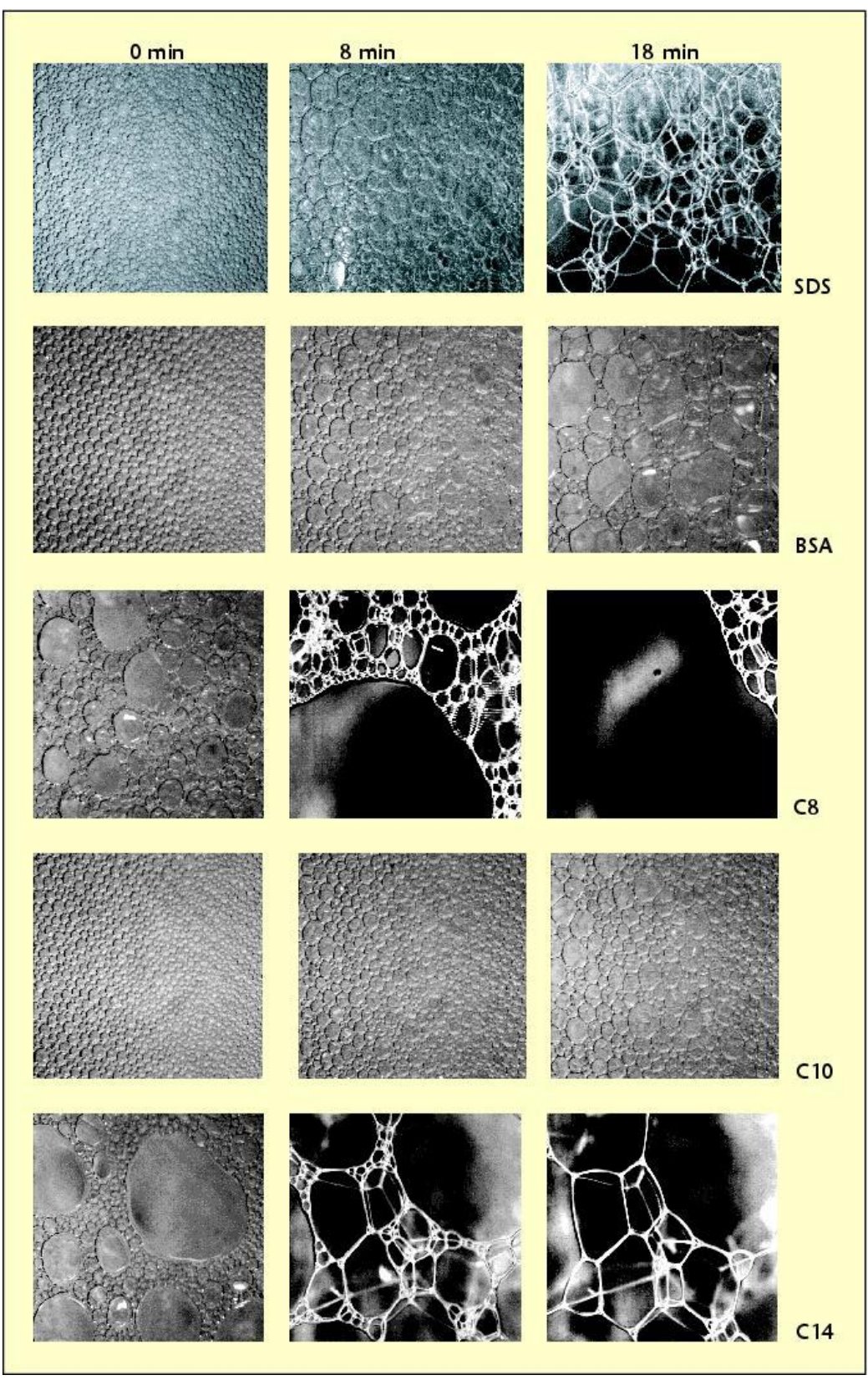

Figure 3. Images de mousses préparées à partir de $S D S, S A B$, dérivés peptidiques $C_{8}, C_{10}, C_{14}$. 


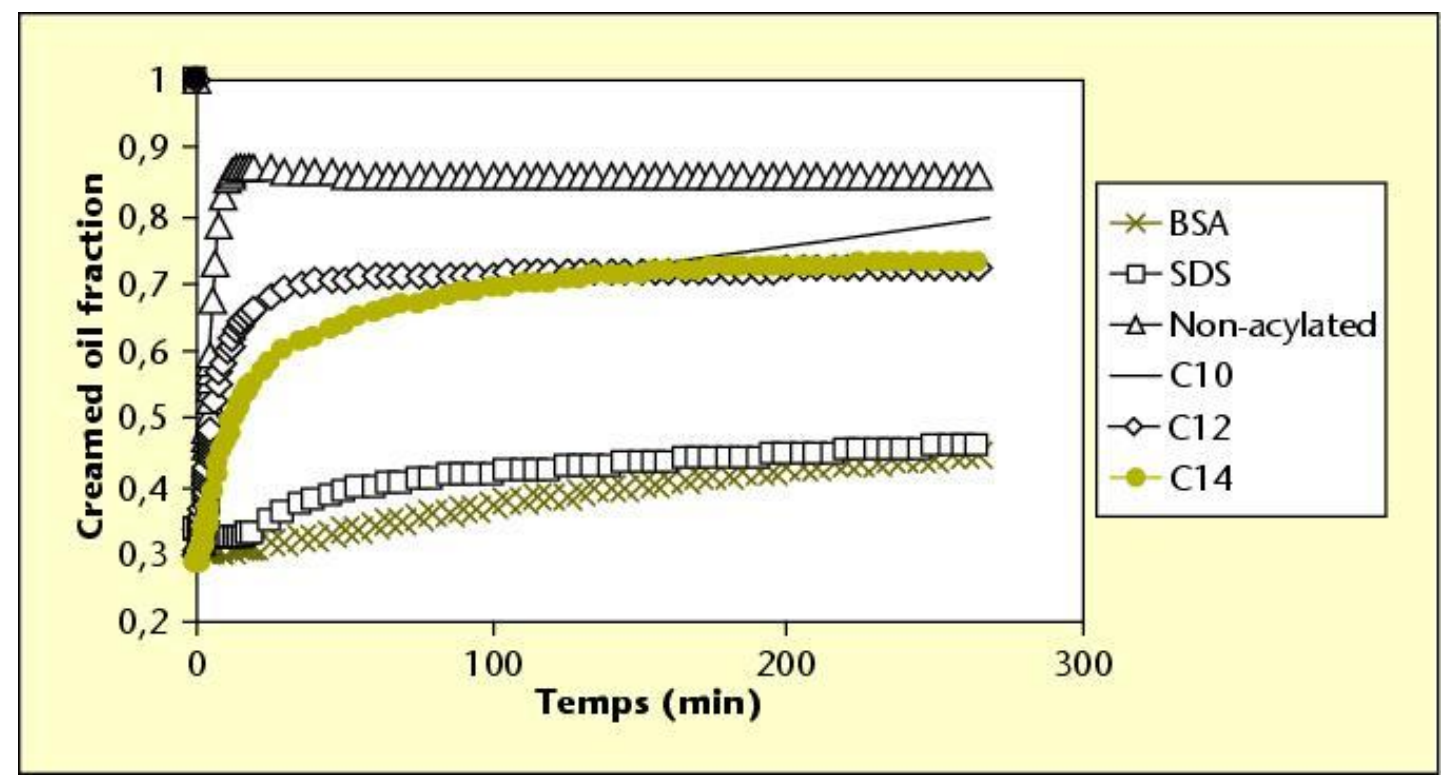

Figure 4. Cinétiques de floculation-crémage d'émulsions préparées avec du SDS, de la $S A B$, des peptides acylés $\mathrm{C}_{10}-\mathrm{C}_{14}$ et non acylés $(1 \mathrm{mg} / \mathrm{ml})$ dans du tampon phosphate de soduim $0,1 \mathrm{M}, \mathrm{pH} 7,0$. Chaque courbe correspond à la moyenne de deux essais.

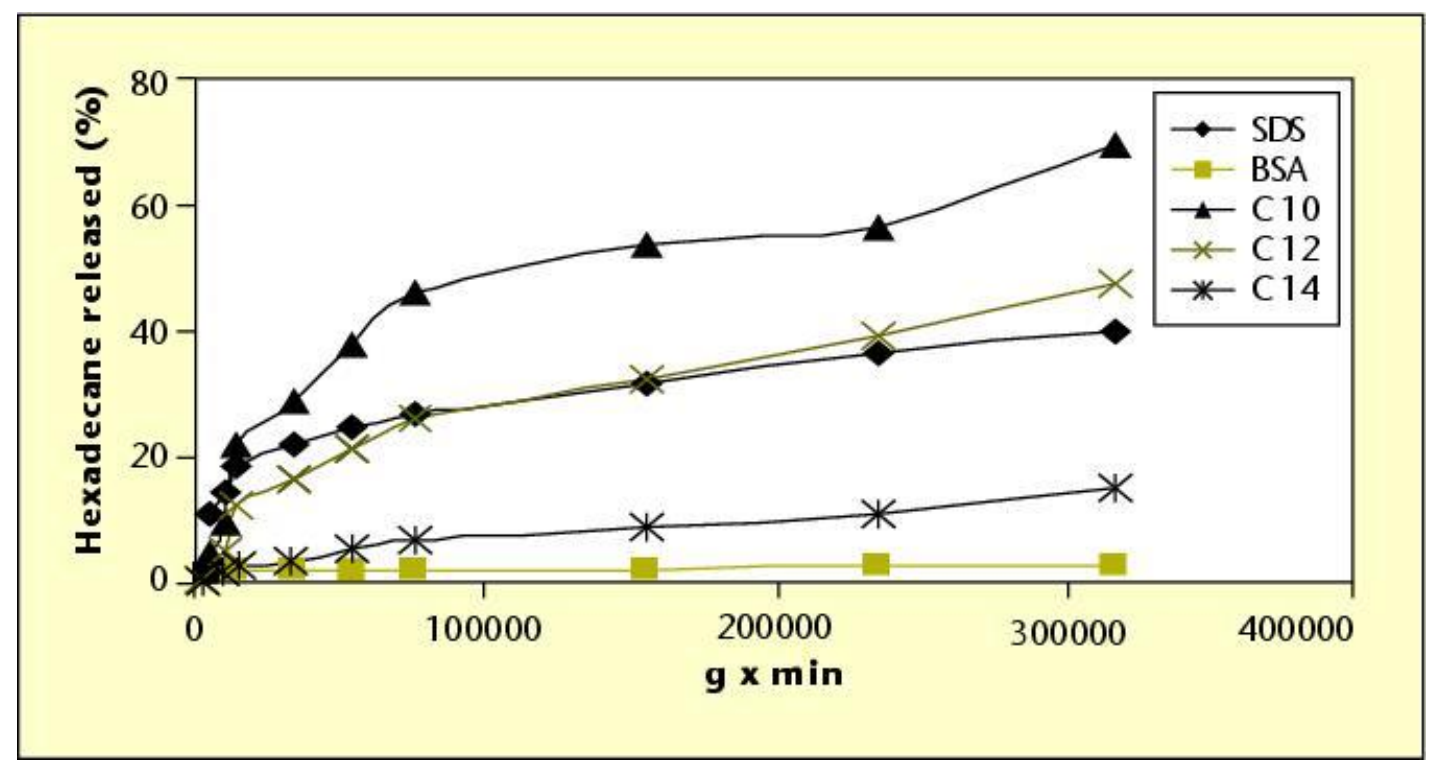

Figure 5. Résistance à la coalescence d'émulsions préparées avec du SDS, de la SAB, des peptides acylés $C_{10}-C_{14}$ et non acylés $(1 \mathrm{mg} / \mathrm{ml})$ dans du tampon phosphate de sodium $0,1 \mathrm{M}, \mathrm{pH} 7,0$. Chaque point correspond à la moyenne de deux essais. 